\title{
Measurement of the educational environment in MBBS teaching program, according to DREEM in College of Medicine, University of Bahri, Khartoum, Sudan
}

This article was published in the following Dove Press journal: Advances in Medical Education and Practice

\author{
Karimeldin MA Salih ${ }^{1,2}$ \\ Muawia EA Idris' \\ Omer A Elfaki ${ }^{3}$ \\ Nasir MN Osman ${ }^{4}$ \\ Saada M Nour ${ }^{5}$ \\ Hind A Elsidig ${ }^{6}$ \\ Rahamatalla M Toam ${ }^{7}$ \\ Walyeldin EM Elfakey' \\ 'Department of Pediatrics, College \\ of Medicine, University of Bahri, \\ Khartoum, Sudan; ${ }^{2}$ Department \\ of Medical Education, Faculty of \\ Medicine, University of Bisha, Bisha, \\ Saudi Arabia; ${ }^{3}$ Department of Health \\ Professional Education, Medical \\ College, University of Batterjee, \\ Jeddah, Saudi Arabia; ${ }^{4}$ Department of \\ Biochemistry, College of Medicine, \\ University of Bahri, Khartoum, \\ Sudan; ${ }^{5}$ Department of Microbiology, \\ College of Medicine, University of \\ Bahri, Khartoum, Sudan; ${ }^{6}$ Department \\ of Pathology, College of Medicine, \\ University of Bahri, Khartoum, \\ Sudan; ${ }^{7}$ Faculty Registrar, College \\ of Medicine, University of Bahri, \\ Khartoum, Sudan
}

\begin{abstract}
Introduction: Learning environment might be defined as anything that can affect the learning directly or indirectly. During the era of accreditation and quality assurance, we are badly in need to evaluate our program strength and pick possible areas for curriculum reform.

Objectives: The aim of this study was to investigate the perception of medical students in the University of Bahri (UB) about the educational environment and analyze the variation of this perception with gender, level of study, type of intake, type of certificate, and accommodation. Methodology: This is a cross-sectional study that was conducted at the Faculty of Medicine, UB, in Sudan during July-August 2017, enrolling 347 students. Dundee Ready Education Environment Measure (DREEM) questionnaire was used as a survey tool for this study.

Results: Overall DREEM average score of $125.2997 / 200$ is perceived. This score is distributed in all DREEM subclasses.

Conclusion: Having some negative perceptions is a huge burden on policymakers, administration, and all stakeholders to revise the whole educational environment at the UB with special efforts needed for curriculum revision, faculty development, mentoring, and other skills development.
\end{abstract}

Keywords: DREEM, measurement, educational environment, perceptions

\section{Introduction}

Many authors have studied the educational environment across all its levels from primary up to the postgraduate level to assess the infrastructures, educational delivery, process, atmospheres, and any contributing factors to learning process academically, administrators, and other factors. ${ }^{1-3}$ Learning environment might be defined as anything that can affect the learning directly or indirectly. ${ }^{4}$ During the era of accreditation and quality assurance, we are badly in need to improve our program strength and pick possible areas for curriculum reform. Studying the educational environment will help us to focus on what we need to keep, develop, and improve. ${ }^{1,5}$ The presentday measurement of the educational environment has become an important issue for health professionals in general and medical education in particular. Although several measures regarding the educational environment have been suggested, the Dundee Ready Education, Environment Measure (DREEM) remains the major reference. ${ }^{6}$ The DREEM has been validated and used widely for the purpose of benchmarking and measurement of the academic environment in educational institutes, mainly in undergraduate curricula and educational institutes at large. ${ }^{7-9}$ DREEM was created through
Correspondence: Walyeldin EM Elfakey Pediatric and Child Health, Medical Educator, College of Medicine, University of Bahri, PO Box 554, Khartoum, Sudan Email walyeldin@aol.co.uk 
the Delphi Process in Dundee, Scotland, UK; its validity and reliability were proven, and then translated into many languages worldwide and adopted by many institutes. ${ }^{4}$ Many universities consider students as the main stakeholders in the educational organization, and their perception toward the educational environment cannot be ignored. ${ }^{7}$ Students' satisfaction is a strong indicator of the achievements, fulfillment of the expected outcomes, and quality of resources, process, environment, and atmospheres. ${ }^{4}$ A strong positive relationship has been seen to exist between students participating in the measurement of learning and their positive perception; in fact, such participation reflects how much students learn, to what extent the area for improvement could be noticed, and where modification could be suggested. ${ }^{10}$ The curriculum is the cornerstone of the educational environment; hence, the attempts toward making this curriculum more attractive and friendly environment toward its execution should be considered, without affecting its quality. ${ }^{11}$ Many authorities, including the World Federation of Medical Education, have stated that the learning environment has strong effects on the skills, knowledge, and cognitive skills to be achieved. ${ }^{4}$

In the Sudanese educational system, students compete for admission to universities by their grades in the final Sudanese secondary school certificate examination, which is held at the national level, shortly known as Sudanese Certificate. International students are required to equate their grades to the Sudanese equivalents. The students who fulfill the criteria for admission to government-sponsored higher education institutions will be admitted and study for free, where those who did not fulfill the government institution's criteria peruse their university education in private institutions. The first group is known as the central pool, while the other is known as the private pool.

\section{The rationale of the study}

To our knowledge, no previous study has been carried out among Sudanese institutions to measure educational environment; many newly high educational institutions have also been introduced over the last 30 years in both the public and private sectors, which have necessitated the educational environment measurement. The international students and academic staff have a high percentage of enrollments and teaching positions at the Sudanese educational institutions. This study aims to investigate the perception of medical students in the University of Bahri (UB) about the educational environment and analyze the variation of this perception with gender, level of study, type of intake, type of certificate, and accommodation.

\section{Methodology}

This is a cross-sectional study conducted at the Faculty of Medicine, UB, during July-August 2017. The total number of medical students was 1,271. The Bachelor of Medicine and Bachelor of Surgery program at UB adopts a mixed (hybrid) curriculum conducted over a period of 6 years. The College of Medicine, UB, teaches basic sciences in the first 3 years and clinical sciences in the next 3 years. The basic modules include a percentage of clinical sciences, and the clinical modules include a percentage of basic sciences. The DREEM questionnaire was used as a survey tool for this study. It consists of 50 items, where each is scored 0-4 on a five-point Likert scale ( $4=$ strongly agree, $3=$ agree, 2 = unsure, $1=$ disagree, and $0=$ strongly disagree). However, 9 out of the 50 items (numbers 4, 8, 9, 17, 25, $35,39,48$, and 50) are negative statements and had to be scored in a reverse manner. Some demographic data were added to the questionnaire, namely gender, level of study, type of intake, type of certificate, and accommodation. The study was announced to students by one of the researchers in each class, and the purpose and anonymity of the survey were explained. The students were asked to take a copy of the questionnaire from the office of medical education if they volunteer to participate and return it after filling. The questionnaire was written in English, which causes no problem, since the language of instruction for the students is English. The predetermined minimum acceptable sample from the whole population of students was calculated to be 296. A total number of 347 students participated. After an extensive discussion between the authors and a medical education expert, we added to the questionnaire the type of admission and accommodation status in addition to the phase of study level (type of admission is usually whether the student is either from the central or private national pool, accommodation is whether the student is staying with his family or renting an apartment, and finally, whether they are in preclinical or clinical classes). The maximum score for the overall DREEM is 200,4 and the maximum scores for the subclasses are as follows: ${ }^{10}$

1. Students' perceptions of learning: 12 questions, maximum score of 48 .

2. Students' perceptions of teachers: 11 questions, maximum score of 44.

3. Students' academic self-perceptions: 8 questions, maximum score of 32 .

4. Students' perceptions of atmosphere: 12 questions, maximum score of 48 . 
5. Students' Social Self-Perceptions: 7 questions, maximum score of 28 .

The following system was adopted for the interpretation of the scores of the overall DREEM and the subclasses:

1. Overall DREEM scores of 0-50, 51-100, 101-150, and 151-200 were considered as very poor, many problems, more positive than negative, and excellent, respectively. ${ }^{11}$

2. Students' perception of learning scores of 0-12, 13-24, and 25-36 were interpreted as very poor, negative, and a more positive approach, respectively. ${ }^{1}$

3. Students' perception of teachers' scores of $0-11,12-22$, 23-33, and 34-44 were considered as abysmal, in need of some retraining, moving in the right direction, and model teachers, respectively. ${ }^{1}$

4. Students' academic self-perception scores of 0-8, 9-16, 17-24, and 25-32 were interpreted as a feeling of total failure, many negative aspects, feeling more on the positive side, and confident, respectively. ${ }^{1}$

5. Students' perception of atmosphere scores of $0-12$, 13-24, 25-36, and 37-48 were considered as a terrible environment, there were many issues that need to change, a more positive atmosphere, and a good feeling overall, respectively,. ${ }^{1}$

6. Students' social self-perception scores of $0-7,8-14$, 15-21, and 22-28 were considered as miserable, not a nice place, not too bad, and very good socially, respectively. ${ }^{1}$

Data analysis was performed using SPSS (v17; SPSS Inc., Chicago, IL, USA). The mean, SD, Student $t$-tests, and oneway analysis of variance were calculated, and $P \leq 0.05$ was considered to be significant.

\section{Ethical approval and consent}

The ethical approval of the study was obtained from the research committee of the Faculty of Medicine, UB. All questionnaire participants have provided written informed consent.

\section{Results}

The total number of medical students at the College of Medicine was 1,271; of whom, 347 participated in the study. Of them, 311 completed the questionnaire, and this represents a response rate of $24.5 \%$. In this study, the overall DREEM evaluation of educational environment measurement was more positive than negative, as well as students' perceptions of learning, students' perceptions of teachers, students' academic self-perceptions, students' perceptions of atmosphere, and students' social self-perceptions $<0.001$ (Table 1). A lot of factors affect our DREEM evaluation such as gender, accommodation, type of certificates, type of admission, and the academic level. Male gender perception through all DREEM classes and subclasses was more positive than negative in contrast to female gender with a significant $P$-value (0.000). Those who stayed with their family have significant positive than negative perception for DREEM in contrast to those who were staying in rented apartments or with their relatives with a significant $P$-value (0.000). No significant difference in student's perception toward a learning environment as measured by DREEM regarding the type of certificate with no difference in students whether they admitted with Sudanese certificates or non-Sudanese certificates. The relationship between the Sudanese certificate and subclass is insignificant for teachers, academic, and atmosphere $(P$-value $=0.014,0.076$, and 0.058$)$ but significant for learning and sociality ( $P$-value $=0.005$ and 0.002$)$. Regarding the type of admission (general or private), it is only significant for perceptual learning $(P$-value $=0.005)$ and insignificant for other subclasses $(P$-value $=0.012,0.013$, and 0.015$)$. The perception of the senior classes for DREEM is more positive than the junior students (Table 2).

\section{Discussion}

This study showed that the overall perception of DREEM, learning, teachers, atmosphere, and social perception is more positive than negative. Male students, the students who stayed with their families, and senior students perceived DREEM as more positive than negative. The relationship between the Sudanese certificate and the subclass is insignificant for

Table I Comparison between Bahri student's perception and international estimate I

\begin{tabular}{llll}
\hline Domain & $\begin{array}{l}\text { U of B } \\
\text { finding }\end{array}$ & Rating & P-value \\
\hline DREEM overall & 132 & More positive than negative & $<0.00$ I \\
Learning & 32 & More positive than negative & \\
Teachers & 30 & More positive than negative & \\
Self-perception & 21 & More positive than negative & \\
Atmosphere & 26 & More positive than negative & \\
Social & I7 & More positive than negative & \\
\hline Domain & BU & Rating & \\
& finding & & \\
\hline DREEM overall & I32 & More positive than negative & $<0.00$ I \\
Learning & 32 & More positive than negative & \\
Teachers & 30 & More positive than negative & \\
Self-perception & 21 & More positive than negative & \\
Atmosphere & 26 & More positive than negative & \\
Social & I7 & More positive than negative & \\
\hline
\end{tabular}

Abbreviations: DREEM, Dundee Ready Education Environment Measure; $U$ of $B$, University of Bahri. 
Table 2 Factors affecting student perception according to DREEM subclass

\begin{tabular}{|c|c|c|c|c|c|c|}
\hline & $\begin{array}{l}\text { Through all } \\
\text { DREEM } 50 \\
\text { questions }\end{array}$ & $\begin{array}{l}\text { Students' } \\
\text { perception } \\
\text { for learning }\end{array}$ & $\begin{array}{l}\text { Students' } \\
\text { perception } \\
\text { for teachers }\end{array}$ & $\begin{array}{l}\text { Students' } \\
\text { academic self- } \\
\text { perception }\end{array}$ & $\begin{array}{l}\text { Students' } \\
\text { perception of } \\
\text { atmosphere }\end{array}$ & $\begin{array}{l}\text { Students' } \\
\text { social } \\
\text { self-perception }\end{array}$ \\
\hline \multicolumn{7}{|l|}{ Gender } \\
\hline M & 159 & 40 & 37 & 27 & 36 & 19 \\
\hline $\mathrm{F}$ & 106 & 27 & 26 & 17 & 21 & 15 \\
\hline$P$-value & \multicolumn{6}{|c|}{0.000 within the gender across subclasses } \\
\hline \multicolumn{7}{|c|}{ Accommodation } \\
\hline With family & 133 & 33 & 31 & 22 & 28 & 17 \\
\hline Others & 106 & 27 & 26 & 17 & 21 & 15 \\
\hline$P$ value & \multicolumn{6}{|c|}{0.000 within the accommodation across subclasses } \\
\hline \multicolumn{7}{|c|}{ Type of certificate } \\
\hline Sudanese & 127 & 32 & 30 & 21 & 27 & 17 \\
\hline Others & 106 & 26 & 26 & 18 & 22 & 14 \\
\hline$P$-value & \multicolumn{6}{|c|}{$\begin{array}{l}\text { Insignificant relationship between Sudanese certificate and subclass for teachers, academic, and atmosphere }(0.014,0.076 \text {, } \\
\text { and } 0.058) \text { but significant for learning and sociality }(0.005 \text { and } 0.002)\end{array}$} \\
\hline \multicolumn{7}{|c|}{ Type of admission } \\
\hline General & 128 & 32 & 30 & 21 & 27 & 17 \\
\hline Others & 108 & 27 & 26 & 18 & 22 & 15 \\
\hline$P$ value & \multicolumn{6}{|c|}{ Only significant for perceptual learning $(0.005)$ and insignificant for other subclasses $(0.012,0.013,0.015$, and 0.025$)$} \\
\hline \multicolumn{7}{|c|}{ 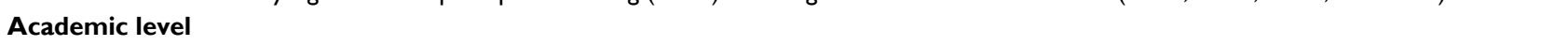 } \\
\hline Early classes & 104 & 27 & 25 & 17 & 20 & 16 \\
\hline Senior classes & 130 & 33 & 31 & 21 & 28 & 17 \\
\hline$P$-value & \multicolumn{6}{|c|}{0.000 significant for senior classes for perception across all subclasses } \\
\hline
\end{tabular}

Abbreviations: DREEM, Dundee Ready Education Environment Measure; M, Male; F, Female.

teachers, academic, and atmosphere $(P$-value $=0.014,0.076$, and 0.058$)$ but significant for learning and sociality $(P$-value $=0.005$ and 0.002 ). The relationship between type of admission (general pole or private) and DREEM is only significant for perceptual learning $(P$-value $=0.005)$ and insignificant for other subclasses $(P$-value $=0.012,0.013,0.015$, and 0.025$)$.

To our knowledge, this is the first type to measure educational environment among Sudanese Universities. According to Miles et al, ${ }^{12}$ DREEM data are to be analyzed with regard to average and subclasses. Our overall finding is considered more positive than negative, which is in alignment with an Indian study, ${ }^{11}$ British School of Osteopathy, ${ }^{4,13}$ Saudi Arabia (Umm Al-Qura University and King Abdulaziz University), ${ }^{13}$ United Arab Emirates, ${ }^{14}$ Kuwait, ${ }^{15}$ Sweden, ${ }^{4}$ Canada, ${ }^{16}$ and Australia. ${ }^{4}$ Also, despite being more positive than negative is a good perception of the student, it should take away our attention from the problems perceived by the students regarding curriculum, teaching, learning, atmosphere, infrastructure, and other social activities. The perception of students toward learning is more positive than negative, which is in agreement with many other studies among Indian medical schools and others. ${ }^{10,11}$ In order to have a good perception of learning, structured teaching, adoption of different instructions methods, enhancing small group teaching in general, and studentcentered learning will improve this problem of perceptual learning. ${ }^{17}$ The perception toward teachers is similar to what stated in an Indian study. ${ }^{11}$ In order to overcome this issue, a proper faculty development, training, and coaching are needed with particular emphasis on the student feedback. Students' academic self-perception as more negative than positive is going with what is happening worldwide. ${ }^{17,18}$ The problem of a busy and detailed curriculum is always the biggest problem for a better performance, whether being an innovative or traditional system. ${ }^{11}$ Curriculum reform and, every time and then, evaluation by all stakeholders will help to overcome this problem. Students' perceptions of the atmosphere are again more positive than negative as perceived by students, and this problem exists elsewhere. ${ }^{11}$ The absence of facilities for different skills and a very busy timetable lead to this conclusion. The same perception for sociality is in alignment with other studies. ${ }^{11,19}$ To avoid this issue, a good psychological, social, financial, advice, proper monitoring, and feedback are needed besides designing tools to discover who is suffering, depressed, stressed, and others.

A significant difference was observed between males and females regarding total response to the questionnaire, mean total DREEM response, and for DREEM subclass with $P$-value $<0.000$. Having more males responding to the questionnaire, better perception of males toward mean total DREEM and DREEM subclasses is not in agreement 
with Arabic and other countries, ${ }^{1,3}$ where only the females perceived mean total DREEM and DREEM subclasses as more positive than negative, and differed also from osteopathic discipline, College of Health and Biomedicine at Victoria University, Melbourne, Australia where no difference in gender was observed. ${ }^{1,20}$ It is not well explained why males perceived DREEM average total and subclass than female and further studies may be needed to elaborate more on this point. A significant difference was observed for the average total DREEM and DREEM subclasses between senior classes (clinical) and junior classes (preclinical), which is in agreement with a study done in Australia 2014. ${ }^{1}$ It is logical for senior classes to perceive DREEM average or subclasses as more positive than negative for many reasons as follows: senior class has developed good experiences in learning, they have better language, and their learning is so motivating since its practical and mainly workplace learning. Those who stayed with their family, looked well cared for, protected from stress and other social problems, financially supported, and, therefore, perceived DREEM average and subclasses as more positive than negative, a finding that disagree with those who are deprived, facing stress, and lacking support. ${ }^{10,21,22}$ Those who were admitted through the Sudanese certificate perceived learning and sociality as more positive than negative in contrast to foreigners. The system of education in other countries is certainly not like the Sudanese one, which might contribute to this more negative perception by non-Sudanese certificate holders. One of these differences is the use of English language as an instructional method in Sudanese Universities; this is not the situation for many neighbor countries who sent their students to study in Sudan. Admission through the general pool (central) leads to more positive perception than negative for learning in contrast to those who were admitted through other routes (private or special intake), which cannot be well understood.

\section{Limitations}

The educational environment is so complicated and very difficult to be covered. The DREEM despite its popularity, validity, and reliability gives predetermined feedback that makes it difficult for all students to respond to it; moreover, it is a lengthy questionnaire that makes 23 students to respond incompletely and 13 not respond at all.

\section{Strength}

This is the first such study to be conducted in a Sudanese high institution, addressing the perception of the students, who are important stakeholders.

\section{Conclusion}

Having more positive than negative brings a huge burden to policymakers, administration, and all stakeholders in keeping these standards in relation to the whole educational environment at the UB with special efforts needed for curriculum revision, faculty development, mentoring, and other skills development. This study identified some issues that may be considered in the curriculum reform, and follow-up studies are needed in the future after applying some curriculum reforms.

\section{Acknowledgments}

We would like to acknowledge the contribution of all at the Faculty of Medicine, the University of Bahri students in completing the questionnaire, and the statistician and college officials for their great help.

\section{Disclosure}

The authors report no conflicts of interest in this work.

\section{References}

1. Vaughan B, Carter A, Macfarlane C, Morrison T. The DREEM, part 1: measurement of the educational environment in an osteopathy teaching program. BMC Med Educ. 2014;14(19):99.

2. Schönrock-Adema J, Bouwkamp-Timmer T, van Hell EA, CohenSchotanus J. Key elements in assessing the educational environment where is the theory? Adv Health Sci Educ Theory Pract. 2012;5(17): $727-742$.

3. Dunne F, McAleer S, Roff S. Assessment of the undergraduate medical education environment in a large UK medical school. Health Educ J. 2006;65(2):149-158.

4. Bakhshialiabad H, Bakhshi M, Hassanshahi G. Students' perceptions of the academic learning environment in seven medical sciences courses based on DREEM. Adv Med Educ Pract. 2015;6:195-203.

5. Harden R. The learning environment and the curriculum. Med Teach. 2001;23(4):335-336.

6. Roff S, McAleer S, Harden RM, et al. Development and validation of the Dundee ready education environment measure (DREEM). Med Teach. 1997;19(4):295-299.

7. Bakhshi H, Bakhshialiabad MH, Hassanshahi GH. Students' perceptions of the educational environment in an Iranian medical school, as measured by the Dundee ready education environment measure. Bangladesh Med Res Counc Bull. 2014;40(1):36-41.

8. Brown T, Williams B, Lynch M. The Australian DREEM: evaluating student perceptions of academic learning environments within eight health science courses. Int J Med Educ. 2011;2:94-101.

9. Varma R, Tiyagi E, Gupta JK. Determining the quality of educational climate across multiple undergraduate teaching sites using the DREEM Inventory. BMC Med Educ. 2005;5(1):8.

10. Aghamolaei T, Fazel I. Medical students' perceptions of the educational environment at an Iranian medical sciences university. BMC Med Educ. 2010;10:87.

11. Kohli V, Dhaliwal U. Medical students' perception of the educational environment in a medical college in India: a cross-sectional study using the Dundee ready education environment questionnaire. $J$ Educ Eval Health Prof. 2013;10:5.

12. Miles S, Swift L, Leinster SJ. The Dundee ready education environment measure (DREEM): a review of its adoption and use. Med Teach. 2012;34(9):e620-e634. 
13. Al-Ayed IH, Sheik SA. Assessment of the educational environment at the college of medicine of King Saud university, Riyadh. East Mediterr Health J. 2008;14(4):953-959.

14. Shehnaz SI, Sreedharn J. Students perception of educational environment transition in United Arab Emirates. Med Teach. 2011;33(1):e37-e42.

15. Bouhaimed M, Thalib L, Doi SA. Perception of the educational environment by medical students undergoing a curricular transition in Kuwait. Med Princ Pract. 2009;18(3):204-208.

16. Till $\mathrm{H}$. Identifying the perceived weaknesses of a new curriculum by means of the Dundee ready education environment measure (DREEM) inventory. Med Teach. 2003;26(1):39-45.

17. Ramani S. Twelve tips for excellent physical examination teaching. Med Teach. 2008;30(9-10):851-856.

18. Abraham R, Ramnarayan K, Vinod P, Torke S. Students' perceptions of learning environment in an Indian medical School. BMC Med Educ. 2008;8:20.
19. Edgren G, Haffling AC, Jakobsson U, McAleer S, Danielsen N. Comparing the educational environment (as measured by DREEM) at two different stages of curriculum reform. Med Teach. 2010;32: e233-e238.

20. Carmody DF, Jacques A, Denz-Penhey H, Puddey I, Newnham JP. Perceptions by medical students of their educational environment for obstetrics and gynaecology in metropolitan and rural teaching sites. Med Teach. 2009;31(12):e596-e602.

21. Al-Hazimi A, Al-hyiani A, Roff S. Perceptions of the educational environment of the medical school in King Abdul Aziz university, Saudi Arabia. Med Teach. 2004;26(6):570-573.

22. Fidelma D, McAleer S, Roff S. Assessment of the undergraduate medical education environment in a large UK medical school. Health Educ J. 2006;65(2):149-158.

\section{Publish your work in this journal}

Advances in Medical Education and Practice is an international, peerreviewed, open access journal that aims to present and publish research on Medical Education covering medical, dental, nursing and allied health care professional education. The journal covers undergraduate education, postgraduate training and continuing medical education including emerging trends and innovative models linking education, research, and health care services. The manuscript management system is completely online and includes a very quick and fair peer-review system. Visit http://www.dovepress.com/testimonials.php to read real quotes from published authors.

Submit your manuscript here: http://www.dovepress.com/advances-in-medical-education-and-practice-journal 